\title{
Role of elevated red cell distribution width on acute kidney injury patients after cardiac surgery
}

\author{
Zhouping Zou ${ }^{1,2,3,4+}$, Yamin Zhuang ${ }^{5 \dagger}$, Lan Liu ${ }^{5+}$, Bo Shen ${ }^{1,2,3,4}$, Jiarui $\mathrm{Xu}^{1,3,4}$, Wuhua Jiang ${ }^{1,3,4}$, Zhe Luo ${ }^{5}$,
} Jie Teng ${ }^{1,2,3,4,6,7^{*}}$ (D), Chunsheng Wang ${ }^{8}$ and Xiaoqiang Ding ${ }^{1,2,3,4,6,7^{*}}$

\begin{abstract}
Background: The aim of the study was to explore associations between elevated red cell distribution width (RDW) and acute kidney injury (AKI) in patients undergoing cardiac surgery (CS-AKI).

Methods: Preoperative, intraoperative and postoperative data of 10,274 patients undergoing cardiac surgery, including demographic data, were prospectively collected from January 2009 to December 2014. Propensity score matching was used on the basis of clinical characteristics and preoperative variables. An elevated RDW was defined as the difference between RDW $24 \mathrm{~h}$ after cardiac surgery and the latest RDW before cardiac surgery.

Results: A total of 10,274 patients were included in the unmatched cohort, and 3146 patients in the propensity-matched cohort. In the unmatched cohort, the overall CS-AKI incidence was 32.8\% $(n=3365)$ with a hospital mortality of 5.5\% $(n=$ 185). In the propensity-matched cohort, the elevated RDW in AKI patients was higher than in patients without AKI $(0.3 \%$ ( 0. $0 \%, 0.7 \%)$ vs $0.5 \%(0.1,1.1 \%), P<0.001)$ and the elevated RDW incidences were $0.4 \%(0.1 \%, 0.9 \%), 0.6 \%(0.2 \%, 1.1 \%)$ and 1 . $1 \%(0.3 \%, 2.1 \%)$ in stage 1,2 and 3 AKI patients $(P<0.001)$. Among propensity-matched patients with CS-AKI, the level of elevated RDW in non-survivors was higher than in survivors $[1.2 \%(0.5 \%, 2.3 \%)$ vs $0.5 \%(0.1 \%, 1.0 \%), P<0.001]$ and a $0.1 \%$ increase in elevated RDW was associated with a $0.24 \%$ higher risk of within-hospital mortality in patients with CS-AKI. Estimating the receiver-operating characteristic (ROC) area under the curve (AUC) showed that an elevated RDW had moderate discriminative power for AKI development (AUC $=0.605,95 \% \mathrm{Cl}, 0.586-0.625 ; P<0.001$ ) and hospital mortality (AUC $=0.716,95 \% \mathrm{Cl}, 0.640-0.764 ; P<0.001$ ) in the propensity-matched cohort.
\end{abstract}

Conclusions: An elevated RDW might be an independent prognostic factor for the severity and poor prognosis of CS-AKI.

Keywords: Acute kidney injury, Cardiac surgery, Prognosis, Red cell distribution width

\section{Background}

Red blood cell distribution width (RDW), which is a marker that describes the morphology of red blood cells and is routinely reported in complete blood counts, is a measurement of erythrocyte variability and heterogeneity. RDW can be expressed either in absolute values (RDW-SD) or as a percentage (RDW \%); the latter approach is more widely used in routine laboratory practice. RDW $s$ together with the value of mean corpuscular

\footnotetext{
* Correspondence: teng.jie@zs-hospital.sh.cn; ding.xiaoqiang@zshospital.sh.cn

${ }^{\dagger}$ Zhouping Zou, Yamin Zhuang and Lan Liu contributed equally to this work. 'Department of Nephrology, Zhongshan Hospital, Shanghai Medical College, Fudan University, No 180 Fenglin Road, Shanghai 200032, China
}

volume (MCV) to classify, diagnose and differentiate the causes of anemia, especially iron-deficiency anemia [1]. Recently, several studies have shown that a high RDW level is a strong independent predictor of increased morbidity and mortality in patients with heart failure, myocardial infarction, paroxysmal atrial fibrillation, primary biliary cirrhosis, chronic hepatitis $\mathrm{C}$, pulmonary embolism, chronic obstructive pulmonary disease (COPD), leukoaraiosis and drug-eluting stent restenosis [2-9]. However, there is limited research regarding the potential association between elevated RDW and the development, severity and prognosis of AKI associated with cardiac surgery (CS-AKI). The present study investigated the potential association between elevated RDW and the development

(c) The Author(s). 2018 Open Access This article is distributed under the terms of the Creative Commons Attribution 4.0 International License (http://creativecommons.org/licenses/by/4.0/), which permits unrestricted use, distribution, and reproduction in any medium, provided you give appropriate credit to the original author(s) and the source, provide a link to the Creative Commons license, and indicate if changes were made. The Creative Commons Public Domain Dedication waiver (http://creativecommons.org/publicdomain/zero/1.0/) applies to the data made available in this article, unless otherwise stated. 
and prognosis of CS-AKI patients in order to identify a novel biomarker for the early diagnosis, clinical severity and prognosis of CS-AKI.

\section{Methods}

\section{Study population}

We retrospectively analyzed data from patients who underwent cardiac surgery from January 2009 to December 2014 in the Zhongshan Hospital affiliated to Fudan University and matched them 1:1 based on propensity scoring. The criteria for exclusion were: age ( $<18$ years), anemia (hemoglobin < $120 \mathrm{~g} / \mathrm{L}$ for males; hemoglobin < $110 \mathrm{~g} / \mathrm{L}$ for females), solitary kidney or history of kidney transplants, severe renal dysfunction with estimated glomerular filtration rate $(\mathrm{eGFR}) \leq 30 \mathrm{~mL} / \mathrm{min} / 1.73 \mathrm{~m}^{2}$ at baseline; preoperative circulatory assist devices, preoperative renal replacement therapy (RRT) or those undergoing a heart transplant; insufficient examination results at baseline.

\section{AKI and RDW definitions}

AKI was defined according to the Kidney Disease Improving Global Outcomes (KDIGO) [10] criteria as described recently [11]: 1) Increase in serum creatinine (Scr) by $\geq 0.3 \mathrm{mg} / \mathrm{dL}(\geq 26.5 \mu \mathrm{mol} / \mathrm{L})$ within $48 \mathrm{~h} ; 2$ ) Increase in Scr to $\geq 1.5$ times baseline, which is known or presumed to have occurred within the prior 7 days; 3) Urine volume $<0.5 \mathrm{~mL} / \mathrm{kg} / \mathrm{h}$ for $6 \mathrm{~h}$ and staged according to the Scr and urine output. An elevated RDW was defined as the difference between the RDW value $24 \mathrm{~h}$ after cardiac surgery and the latest RDW value before cardiac surgery. The reference range for RDW value was $11.0-16.0 \%$ at the Zhongshan Hospital affiliated to Fudan University.

\section{Clinical trial design and methods}

Informed consent was provided by all of the patients according to hospital guidelines. At admission, baseline blood testing, echocardiography and electrocardiography were performed. Recorded clinical data were preoperative baseline characteristics and blood tests, complications, preoperative renal function (determined by the latest serum creatinine value before cardiac surgery) as well as perioperative data about cardiac functions according to the 1994 New York Heart Association (NYHA) classification and intraoperative variables which included cardiac output data derived from echocardiography, cardiopulmonary bypass (CPB) and aortic cross-clamp (ACC) durations in minutes, as well as types of surgery. The recorded postoperative variables were mechanical ventilation duration and urine output during the first post-surgery $24 \mathrm{~h}$ as well as AKI incidence and stage in addition to hospital mortality.

\section{Outcomes}

The primary endpoint was the occurrence of AKI. The secondary endpoint was all cause of mortality.

\section{Statistical analysis}

All statistical analyses were performed using SPSS Statistics for Windows (Version 22.0. Armonk, NY: IBM Corp). Propensity score matching was used to adjust for observed differences in characteristics of patients with and without AKI. Comparisons of the differences in the baseline characteristics were performed using a Student's $t$-test for parametric data and a Mann-Whitney U-test for non-parametric data. Categorical variables were compared using a chi-square test or Fisher's exact test.

Associations of pre-, intra-, post-operative and demographic data were tested with Wilcoxon rank-sum or two-sample $t$-tests for continuous and a Pearson $\chi^{2}$ test for categorical variables. Continuous variables are presented as mean \pm standard deviation or median (interquartile range $[\mathrm{IQR}]$ ) and categorical variables are shown as frequency counts (\%). A multivariable logistic regression model was used for estimation of unadjusted and adjusted odds ratios (ORs). Pearson's and Spearman correlation tests were used to determine the correlation between variables. Receiver operator characteristic (ROC) curves were constructed to analyze the discriminating power of elevated RDW for predicting the development of AKI and all-cause hospital mortality. ROC curve analysis statistics were determined with area under the curve (AUC) (95\% CI) estimated by bootstrapping. Two-tailed P-values < 0.05 were considered to be statistically significant for all analyses.

\section{Results}

Patient characteristics of the study population Unmatched cohort

A total of 10,274 patients undergoing cardiac surgery were enrolled; most were men (56.7\%). The overall CS-AKI incidence was $32.8 \%(n=3365)$ with a hospital mortality of $5.5 \%(n=185)$. The mean age at hospital admission was 53.3 years $( \pm$ SD 13.9). The mean age, proportion of males mean body mass index (BMI), hemoglobin, white blood cells (WBC), serum creatinine (SCr), blood urea nitrogen (BUN), serum uric acid (SUA), CPB time, elevated RDW, preoperative proportions of hypertension, diabetes mellitus (DM), coronary angiography, chronic heart failure (NYHA > II), aortic cross-clamp (ACC) time were increased in the AKI group, whereas baseline albumin was decreased (Table 1).

\section{Risk factors for the development of CS-AKI}

All the variables recorded in Table 1 were put into a univariate logistic regression model and the detailed results are presented in Table 2. The odds ratios of CS-AKI in the unmatched cohort for the independent risk factors that were computed from the multivariate logistic regression model are shown in Table 3. The independent risk factors that were computed from the multivariate logistic regression 
Table 1 Comparison of the Demographic and Baseline Characteristics of unmatched and matched AKI and non-AKI groups

\begin{tabular}{|c|c|c|c|c|c|c|}
\hline & \multicolumn{2}{|c|}{ Unmatched Cohort $(n=10,274)$} & \multirow[t]{2}{*}{$P$-value } & \multicolumn{2}{|c|}{ Matched Cohort $(n=3146)$} & \multirow[t]{2}{*}{$P$-value } \\
\hline & $\begin{array}{l}\text { Non-AKI group } \\
(n=6909)\end{array}$ & $\begin{array}{l}\text { AKI group } \\
(n=3364)\end{array}$ & & $\begin{array}{l}\text { Non-AKI group } \\
(n=1573)\end{array}$ & $\begin{array}{l}\text { AKl group } \\
(n=1573)\end{array}$ & \\
\hline Age (years) & $51.7 \pm 14.0$ & $56.8 \pm 12.3$ & $<0.001$ & $54.6 \pm 12.0$ & $54.4 \pm 12.1$ & 0.782 \\
\hline Male, sex & $3584(51.9 \%)$ & $2233(66.6 \%)$ & $<0.001$ & $966(61.4 \%)$ & $913(58.0 \%)$ & 0.059 \\
\hline \multicolumn{7}{|l|}{ Comorbidities } \\
\hline Hypertension & $1748(25.3 \%)$ & 1177 (35\%) & $<0.001$ & $422(26.8 \%)$ & $457(29.1 \%)$ & 0.177 \\
\hline DM & $628(9.1 \%)$ & $386(11.5 \%)$ & $<0.001$ & 139 (8.8\%) & $151(9.6 \%)$ & 0.498 \\
\hline Creatinine, $\mu \mathrm{mol} / \mathrm{L}$ & $75.7 \pm 20.6$ & $83.6 \pm 29.5$ & $<0.001$ & $77.1 \pm 17.3$ & $77.8 \pm 19.7$ & 0.325 \\
\hline eGFR & $93.0 \pm 22.1$ & $87.3 \pm 25.3$ & $<0.001$ & $91.5 \pm 20.7$ & $91.0 \pm 24.1$ & 0.566 \\
\hline BUN & $6.1 \pm 2.1$ & $7.0 \pm 2.8$ & $<0.001$ & $6.2 \pm 1.9$ & $6.3 \pm 1.8$ & 0.063 \\
\hline Albumin baseline & $40.6 \pm 3.3$ & $40.1 \pm 3.3$ & $<0.001$ & $40.0 \pm 3.4$ & $39.9 \pm 3.5$ & 0.162 \\
\hline Hemoglobin, g/dL & $136.5 \pm 14.6$ & $137.3 \pm 15.9$ & 0.005 & $134.7 \pm 17.0$ & $133.6 \pm 18.7$ & 0.093 \\
\hline WBC, $1000 / \mu \mathrm{L}$ & $6.4 \pm 2.0$ & $6.5 \pm 2.2$ & 0.033 & $6.4 \pm 2.4$ & $6.4 \pm 2.0$ & 0.532 \\
\hline Elevated RDW, \% & $0.3(0.0,0.6)$ & $0.5(0.1,1.0)$ & $<0.001$ & $0.3(0.0,0.7)$ & $0.5(0.1,1.1)$ & $<0.001$ \\
\hline Platelet fl & $188.8 \pm 56.7$ & $177.3 \pm 56.4$ & $<0.001$ & $189.2 \pm 62.1$ & $178.2 \pm 58.7$ & $<0.001$ \\
\hline $\mathrm{BMl}, \mathrm{kg} / \mathrm{m}^{2}$ & $22.9 \pm 3.0$ & $23.5 \pm 3.2$ & 0.013 & $22.6 \pm 3.2$ & $23.3 \pm 3.7$ & $<0.001$ \\
\hline SUA & $351.0 \pm 104.7$ & $394.0 \pm 138.6$ & $<0.001$ & $355.6 \pm 101.0$ & $377.0 \pm 108.6$ & $<0.001$ \\
\hline \multicolumn{7}{|l|}{ NYHA functional class } \\
\hline$|-| \mid$ & $3420(49.5 \%)$ & $1370(40.7)$ & $<0.001$ & $755(48.0 \%)$ & $610(38.8 \%)$ & $<0.001$ \\
\hline III-IV & 3489 (50.5\%) & 1995 (59.3) & $<0.001$ & $818(52.0 \%)$ & $963(61.2 \%)$ & $<0.001$ \\
\hline LVEF\% & $62.4 \pm 8.3$ & $61.4 \pm 19.3$ & 0.071 & $62.1 \pm 8.1$ & $61.3 \pm 9.4$ & 0.092 \\
\hline CPB time (min) & $81.0(65.0,105.0)$ & $101.0(78.0,128.0)$ & $<0.001$ & $80.5(65.0,105.0)$ & $99.0(78.0,126.0)$ & $<0.001$ \\
\hline ACC time (min) & $48.0(36.0,67.0)$ & $58.0(43.0,78.0)$ & $<0.001$ & $48.0(37.0,67.0)$ & $55.0(41.0,78.0)$ & $<0.001$ \\
\hline $\begin{array}{l}\text { Pre-operative coronary } \\
\text { angiography n (\%) }\end{array}$ & $2543(36.8)$ & $1528(45.4)$ & $<0.001$ & $690(43.9 \%)$ & $617(39.2 \%)$ & 0.009 \\
\hline $\begin{array}{l}\text { Time interval between } \\
\text { coronary angiogram and } \\
\text { cardiac surgery (days) }\end{array}$ & $4(2,6)$ & $4(2,6)$ & 0.212 & $3(2,6)$ & $3(2,6)$ & 0.981 \\
\hline
\end{tabular}

$A K I$ acute kidney injury, $B M I$ body mass index, DM diabetes mellitus, WBC white blood cell, $R D W$ red cell distribution width, $B U N$ blood urea nitrogen, $e G F R$ estimated glomerular filtration rate SUA serum uric acid, NYHA New York Heart Association, LVEF left ventricular ejection fraction, CPB cardiopulmonary bypass, ACC Aortic cross-clamp

model were age $(\mathrm{OR}=1.036,95 \% \mathrm{CI}: 1.029-1.042, P$ $<0.001)$, male $(\mathrm{OR}=1.873,95 \%$ CI: $1.622-2.164, P$ $<$ 0.001), BMI (OR =1.035, 95\% CI: 1.016-1.055, $P$ $<$ 0.001), elevated RDW (OR $=1.302,95 \%$ CI: 1.209-1.401, $P<0.001)$, BUN (OR $=1.076,95 \%$ CI: 1.041-1.112, $P$ $<0.001)$, SUA (OR $=1.002,95 \%$ CI: 1.001-1.003, $P$ $<0.001)$, CPB time (additional $30 \mathrm{~min})(\mathrm{OR}=1.62795 \%$ CI: $1.491-1.775, P<0.001)$.

\section{The association between elevated RDW and the} development and prognosis of CS-AKI

The AKI group had a higher level of elevated RDW than the non-AKI group $[0.5 \%(0.1 \%, 1.0 \%)$ vs $0.3 \%(0,0.6 \%)$, $P<0.001]$. Each $0.1 \%$ increment in elevated RDW was associated with a $1.1 \%$ higher risk of CS-AKI. The elevated $\mathrm{RDW}$ were $0.4 \%(0.1 \%, 0.9 \%), 0.5 \%(0.2 \%, 1.0 \%)$, $0.8 \%(0.3 \%, 1.7 \%)$ in stages 1,2 and 3 of AKI, respectively. An increment in elevated RDW was associated with having a higher stage of AKI $(P=0.02)$. The patients were divided into two groups according to whether the RDW baseline was $\geq 16.0 \%$. The incidence of CS-AKI in the RDW group (> 16.0\%) was significantly higher than in the RDW group $(\leq 16.0 \%, 33.9 \%$ vs $38.4 \%, P<0.001)$. The adjusted odds ratio of CS-AKI development in the RDW group $>16.0 \%$ was 1.67 -fold, compared with RDW $\leq$ in the $16.0 \%$ group. Among patients with CS-AKI, the level of elevated RDW in non-survivors was higher than survivors[1.1\% (0.4\%, 2.0\%) vs $0.4 \%(0.1 \%, 0.9 \%), P<0.001]$. There was no significant difference in elevated RDW between non-survivors and survivors without CS-AKI $[0.4 \%(-0.1 \%, 0.9 \%)$ vs $0.3 \%$ (0.0, 0.6\%), $P=0.875]$. A $0.1 \%$ increase in elevated RDW was associated with a $0.24 \%$ higher risk of within-hospital mortality in those patients with CS-AKI. 
Table 2 Univariate logistic regression analysis of risk factors for CS-AKI

\begin{tabular}{|c|c|c|c|c|c|c|}
\hline & \multicolumn{3}{|c|}{ Before Propensity Matching } & \multicolumn{3}{|c|}{ After Propensity Matching } \\
\hline & $\mathrm{OR}$ & $95 \% \mathrm{Cl}$ & $P$-value & $\mathrm{OR}$ & $95 \% \mathrm{Cl}$ & $P$-value \\
\hline Age & 1.030 & $1.027-1.034$ & $<0.001$ & 0.999 & $0.993-1.005$ & 0.782 \\
\hline Male & 1.825 & $1.680-1.994$ & $<0.001$ & 0.869 & $0.754-1.002$ & 0.754 \\
\hline $\mathrm{BMI}$ & 1.066 & $1.051-1.081$ & $<0.001$ & 1.063 & $1.037-1.090$ & $<0.001$ \\
\hline HTN & 1.588 & $1.452-1.736$ & $<0.001$ & 1.117 & $0.956-1.305$ & 0.164 \\
\hline $\mathrm{DM}$ & 1.305 & $1.145-1.487$ & $<0.001$ & 1.095 & $0.860-1.395$ & 0.46 \\
\hline Pre-operative coronary angiography & 1.421 & $1.313-1.553$ & $<0.001$ & 0.826 & $0.717-0.952$ & 0.08 \\
\hline $\mathrm{Hb}$ & 1.004 & $1.001-1.007$ & $<0.001$ & 0.997 & $0.993-1.001$ & 0.093 \\
\hline WBC & 1.019 & $1.002-1.042$ & $<0.001$ & 0.990 & $0.958-1.022$ & 0.533 \\
\hline Plt & 0.996 & $0.996-0.997$ & 0.633 & 0.997 & $0.996-0.998$ & 0.601 \\
\hline Elevated RDW & 1.497 & $1.419-1.578$ & $<0.001$ & 1.192 & $1.126-1.262$ & $<0.001$ \\
\hline BUN & 1.178 & $1.147-1.193$ & $<0.001$ & 1.036 & 0998-1.076 & 0.064 \\
\hline Scr & 1.015 & $1.013-1.017$ & $<0.001$ & 1.002 & $0.998-1.006$ & 0.325 \\
\hline eGFR & 0.989 & $0.987-0.991$ & 0.002 & 0.999 & $0.996-1.002$ & 0.004 \\
\hline UA & 1.003 & $1.003-1.004$ & $<0.001$ & 1.002 & $1.001-1.003$ & $<0.001$ \\
\hline Alb & 0.954 & $0.941-0.965$ & $<0.001$ & 0.986 & $0.996-1.006$ & 0.162 \\
\hline CPB time (every $30 \mathrm{~min}$ ) & 1.498 & $1.439-1.559$ & $<0.001$ & 1.490 & $1.385-1.603$ & $<0.001$ \\
\hline ACC time (every $20 \mathrm{~min}$ ) & 1.295 & $1.248-1.343$ & $<0.001$ & 1.253 & $1.176-1.336$ & $<0.001$ \\
\hline
\end{tabular}

$A K I$ acute kidney injury, $B M I$ body mass index, HTN hypertension, DM diabetes mellitus, $H b$ hemoglobin, WBC white blood cell, $P I t$ platelet, $R D W$ red cell distribution width, BUN blood urea nitrogen, Scr serum creatinine, eGFR estimated glomerular filtration rate, SUA serum uric acid, CPB cardiopulmonary bypass, ACC Aortic cross-clamp

\section{Bivariate correlation analyses of elevated RDW and various clinical and laboratory parameters of the study population in the unmatched cohort}

The results of bivariate correlation analyses showed that there was a positive correlation between elevated RDW and age $(r=0.188, P<0.001)$, HTN $(r=0.080, P<0.001)$, $\mathrm{DM}(r=0.052, P<0.001), \mathrm{BUN}(r=0.039, P<0.001), \mathrm{CPB}$ time $(r=0.159, P<0.001)$, ACC time $(r=0.136, P$ $<0.001)$, AKI stage $(r=0.171, P<0.001)$ and a negative correlation with male $(r=-0.096, P<0.001), \operatorname{BMI}(r=-$ 0.045, $P=0.01)$, hemoglobin $(r=-0.147, P<0.001)$, Albumin $(r=-0.047, P<0.001)$, and eGFR $(r=-0.105, P$ $<0.001$ ) (see Table 4).

Table 3 Multivariate logistic regression analysis of risk factors for CS-AKI in the unmatched Cohort

\begin{tabular}{llll}
\hline & OR & $95 \% \mathrm{Cl}$ & $P$-value \\
\hline Age & 1.036 & $1.029-1.042$ & $<0.001$ \\
Male & 1.873 & $1.622-2.164$ & $<0.001$ \\
BMI & 1.035 & $1.016-1.055$ & $<0.001$ \\
Elevated RDW & 1.302 & $1.209-1.401$ & $<0.001$ \\
BUN & 1.076 & $1.041-1.112$ & $<0.001$ \\
SUA & 1.002 & $1.001-1.003$ & $<0.001$ \\
CPB time (every 30 min) & 1.627 & $1.491-1.775$ & $<0.001$ \\
\hline
\end{tabular}

$A K I$ acute kidney injury, $B M I$ body mass index, $R D W$ red cell distribution width, $B U N$ blood urea nitrogen, SUA serum uric acid, $C P B$ cardiopulmonary bypass

\section{Propensity-matched cohort}

Propensity score matching created a matched cohort of 1573 in each group. In this matched cohort, few differences remained in non-AKI and AKI groups (Table 1). The results of univariate logistic regression model are presented in Table 2. The odds ratios of CS-AKI in the matched cohort for the independent risk factors that were computed from the multivariate logistic regression model are shown in Table 5. In the matched cohort, the elevated RDW in AKI patients was higher than in patients without AKI $(0.3 \%$ $(0.0 \%, 0.7 \%)$ vs $0.5 \%(0.1,1.1 \%), P<0.001)$. The elevated RDW incidences were $0.4 \%(0.1 \%, 0.9 \%), 0.6 \%(0.2 \%, 1.1 \%)$ and $1.1 \%(0.3 \%, 2.1 \%)$ in stage 1,2 and 3 AKI patients $(P$ $<0.001)$. Among patients with CS-AKI, the level of elevated RDW in non-survivors was higher than in survivors [1.2\% $(0.5 \%, 2.3 \%)$ vs $0.5 \%(0.1 \%, 1.0 \%), P<0.001]$ and a $0.1 \%$ increase in elevated RDW was associated with a $0.24 \%$ higher risk of within-hospital mortality in patients with CS-AKI.

\section{Receiver-operating characteristic curve analysis for} prediction of the development and prognosis of CS-AKI in the matched cohort by elevated red cell distribution width level

To assess discrimination of RDW for all causes of hospital mortality, we used receiver-operating characteristic (ROC) analysis and determined the area under the curve (AUC). The cut-off value of elevated RDW for predicting CS-AKI 
Table 4 Bivariate correlation analyses of elevated RDW and various clinical and laboratory parameters of the study population in the umatched Cohort

\begin{tabular}{lll}
\hline & $r$ & $P$-value \\
\hline Age & 0.188 & $<0.001$ \\
Male & -0.096 & $<0.001$ \\
BMI & -0.045 & 0.01 \\
HTN & 0.098 & $<0.001$ \\
DM & 0.052 & $<0.001$ \\
Hb & -0.147 & $<0.001$ \\
WBC & -0.010 & 0.292 \\
Alb & -0.047 & $<0.001$ \\
BUN & 0.039 & $<0.001$ \\
SCr & 0.020 & 0.040 \\
eGFR & -0.105 & $<0.001$ \\
SUA & -0.010 & 0.292 \\
CPB time & 0.159 & $<0.001$ \\
ACC time & 0.136 & $<0.001$ \\
AKI stage & 0.171 & $<0.001$ \\
\hline BMI body massindex,HTN &
\end{tabular}

$B M I$ body mass index, $H T N$ hypertension, $D M$ diabetes mellitus, $H b$ hemoglobin, $W B C$ white blood cell, $A l b$ albumin, $B U N$ blood urea nitrogen, $S C r$ serum creatinine, eGFR estimated glomerular filtration rate, $S U A$ serum uric acid, CPB cardiopulmonary bypass, ACC Aortic cross-clamp, AKI acute kidney injury

was $0.30 \%$. The AUC value was 0.605 (95\% CI: 0.586$0.625, P<0.001)$ and the sensitivity, specificity, positive likelihood ratio and negative likelihood ratio of elevated RDW were $51.6 \%, 63.3 \%, 1.41$ and 0.76 , respectively.

Elevated RDW had moderate discriminative power for predicting the death of CS-AKI patients. The cut-off value of elevated RDW for predicting death of CS-AKI patients was 0.75\%; AUC value 0.716 (95\% CI: 0.640$0.764, P<0.001)$ and the sensitivity, specificity, positive likelihood ratio and negative likelihood ratio of elevated RDW were $71.4 \%, 65.5 \%, 1.53$ and 0.83 , respectively.

\section{Discussion}

The main finding of the present study was the establishment of an independent association between elevated RDW and in-hospital mortality with CS-AKI. An elevated

Table 5 Multivariate logistic regression analysis of risk factors for CS-AKI in the matched Cohort

\begin{tabular}{llll}
\hline & OR & $95 \% \mathrm{Cl}$ & $P$-value \\
\hline BMI & 1.078 & $1.046-1.111$ & $<0.001$ \\
Elevated RDW & 1.159 & $1.074-1.251$ & $<0.001$ \\
EGFR & 1.006 & $1.001-1.010$ & 0.015 \\
SUA & 1.002 & $1.001-1.003$ & $<0.001$ \\
CPB time (every 30 min) & 1.493 & $1.363-1.635$ & $<0.001$ \\
\hline
\end{tabular}

$A K I$ acute kidney injury, $B M I$ body mass index, $R D W$ red cell distribution width, eGFR estimated glomerular filtration rate, $S U A$ serum uric acid, $C P B$ cardiopulmonary bypass
RDW remains a significant predictor for the severity and mortality of CS-AKI patients following multivariable adjustments. However, there was no clear evidence to show that the elevated RDW was a significant predictor for the development of CS-AKI and there was no significant effect modification between an elevated RDW and in-hospital mortality in those patients without CS-AKI.

A previous study showed that RDW is a strong and independent prognostic predictor of mortality and morbidity in patients with CKD, which described RDW changes in CKD patients undergoing hemodialysis for the first time [12]. Recent research indicates that a higher RDW was independently associated with increased cardiovascular disease (CVD) mortality in peritoneal dialysis (PD) and in end stage renal disease (ESRD) patients [13, 14]. Mario Sičaja et al. found that for each $1 \%$ point increase in the RDW level the one-year all cause mortality risk was increased by $54 \%$ in patients requiring chronic dialysis [15].

Recent clinical research on RDW and AKI have focused on RDW and contrast-induced AKI in percutaneous coronary interventions (CI-AKI). The results showed that RDW has become a recent target of investigations into new predictors of kidney function and mortality after percutaneous coronary interventions (PCI) [2, 16-18]. The study by Atsushi Mizuno et al. analyzed 102 patients with ST-elevation myocardial infarction and found that RDW was an independent variable predicting CI-AKI and has additional value to the Mehran risk score for predicting contrast-induced (CI)-AKI [19]. Other researchers have investigated the association between RDW and CI-AKI and suggested that RDW was associated independently with the development of CI-AKI and may well be a useful marker in CI-AKI risk stratification [16, 20].

To the best of our knowledge, our study is the first research in the literature that has explored the association between elevated RDW and CS-AKI. However, it needs more research to establish an association between elevated RDW and CS-AKI incidence. The mechanisms underlying the association between higher RDW and poor prognosis have not been clearly determined. Several possible explanations can be considered in cardiac surgery patients. Hemolysis, blood loss, hypothermia, ischemia, and perfusion injury as well as neutrophil activation during $\mathrm{CPB}$ play a pivotal role in oxidative stress and the associated activation of inflammation. In particular, ischemia and reperfusion injury during cardiac surgery can lead to the generation of pro-inflammatory mediators [21-24]. In our research, the results of bivariate correlation analyses showed that there was a positive correlation between elevated RDW and the $\mathrm{CPB}$ and $\mathrm{ACC}$ times. Inflammation may play a role in the regulation of RDW by direct myelo-suppression of erythroid precursors, decreasing erythropoietin production, reducing the bioavailability of iron and by promoting erythropoietin resistance and red cell apoptosis [25-29]. 
Related research [30-34] has demonstrated that oxidative stress increases anisocytosis by disrupting erythropoiesis and altering blood cell membrane deformability and thus the red blood cell circulation lifetime, ultimately leading to an increase in RDW. In addition, during $\mathrm{CPB}$, ischemia and reperfusion play a pivotal role in oxidative stress by initiating a series of biochemical events [22]. However, in our study, we were not able to adjust the analysis to include inflammatory markers, $\mathrm{C}$-reactive protein (CRP) and other factors, as these were not routinely measured at patient admission.

The renin-angiotensin-aldosterone system (RAAS) is activated by arterial underfilling caused by $\mathrm{CPB}$, heart failure, shock and so on after cardiac surgery. The activation of the RAAS system and adrenergic hormone release could cause increased RDW with erythropoiesis, resulting in a poor prognosis [34]. There is evidence suggesting that angiotensin II acts as a growth factor for erythroid precursors as well as an erythropoietin secretagogue resulting in an increment in RDW due to macrocytosis from skipped cell divisions [35].

RDW is increased in conditions such as malnutrition and deficiencies such as in vitamin B12 [36], iron [37] or folic acid [38], increased red cell destruction (such as hemolysis), or after blood transfusion. Previous research has reported that RDW was correlated negatively with nutrition in heart failure [39] and HD patients [13]. This latter study showed that elevated RDW was negatively correlated with the albumin level. Patients with malnutrition have a higher risk of infection and adverse outcomes and elevated RDW and poor prognosis may relate to the fact that there is an interaction between malnutrition and inflammation.

The present research work has several limitations. First, it was a retrospective design from a single central pool of patients. Second, we did not measure hematopoietic factors (including iron, vitamin B12, folate, etc.) that may influence RDW. Third, though neurohumoral activation and inflammation may be a mechanistic link between elevated RDW and poor outcomes, we did not assess laboratory markers including CRP, other pro-inflammatory cytokines, norepinephrine and angiotensin II. Despite these limitations, a major strength of the present study is that it had a sufficient number of patients undergoing cardiac surgery to ensure adequate reliability of our incidence and mortality estimates. Future studies of a larger cohort of single center pool patients will be required to confirm the results of the present investigation.

\section{Conclusion}

The results of the present study suggest, that an elevated RDW might be an independent prognostic factor for the severity and poor prognosis of CS-AKI.

\section{Abbreviations}

ACC: Aortic cross-clamp; AKI: Acute kidney injury; AUC: Area under the curve; BMI: Body mass index; BUN: Blood urea nitrogen; $\mathrm{Cl}-\mathrm{AKI}$ : AKI in percutaneous coronary interventions; COPD: Chronic obstructive pulmonary disease; CPB: Cardiopulmonary bypass; CRP: C-reactive protein; CS-AKI: AKI in patients undergoing cardiac surgery; CVD: Cardiovascular disease; DM: Diabetes mellitus; eGFR: Estimated glomerular filtration rate; ESRD: End stage renal disease; IQR: Interquartile range; KDIGO: Kidney Disease Improving Global Outcomes; LOS: Length-of-stay; MCV: Mean corpuscular volume; ORs: Odds ratios; PCl: Percutaneous coronary interventions; PD: Peritoneal dialysis; RAAS: Renin-angiotensin-aldosterone system; RDW: Red cell distribution width; ROC: Receiver-operating characteristic; RRT: Renal replacement therapy; Scr: Serum creatinine; SUA: Serum uric acid; WBC: White blood cells

\section{Funding}

The work was supported by The Project of Shanghai Municipal Commission of Health and Family Planning [grant number 15GWZK0502]; The Projects of Science and Technology Commission of Shanghai Municipality [grant number 14DZ2260200]; The Project of Shanghai Key Laboratory of Kidney and Blood Purification [grant number 17140902300].

\section{Availability of data and materials}

The datasets used and/or analysed during the current study available from the corresponding author on reasonable request.

\section{Authors' contributions}

$Z Z, Y Z, L L, J T$ and $X D$ were responsible for the conception and design of the study. ZZ, YZ, LL, BS, JX, WJ, ZL and JT were responsible for acquisition and analysis of data; furthermore, ZZ, BS, JX, WJ and ZL were in charge of statistical analysis. ZZ, YZ and LL drafted the manuscript; JT, CW and XD revised and commented the draft. All authors read and approved the final version of the manuscript.

\section{Ethics approval and consent to participate}

This study was approved by the ethical committee of Zhongshan Hospital affiliated to Fudan University, and informed consent was provided by all of the patients according to hospital guidelines.

\section{Consent for publication}

Not applicable.

\section{Competing interests}

The authors declare that they have no competing interests.

\section{Publisher's Note}

Springer Nature remains neutral with regard to jurisdictional claims in published maps and institutional affiliations.

\section{Author details}

'Department of Nephrology, Zhongshan Hospital, Shanghai Medical College, Fudan University, No 180 Fenglin Road, Shanghai 200032, China. ${ }^{2}$ Shanghai Medical Center of Kidney, No 180 Fenglin Road, Shanghai 200032, China. ${ }^{3}$ Shanghai Institute for Kidney and Dialysis, No 180 Fenglin Road, Shanghai 200032, China. ${ }^{4}$ Shanghai Key Laboratory of Kidney and Blood Purification, No 180 Fenglin Road, Shanghai 200032, China. ${ }^{5}$ Department of Critical Care Medicine, Zhongshan Hospital, Shanghai Medical College, Fudan University, No 180 Fenglin Road, Shanghai 200032, China. ${ }^{6}$ Hemodialysis Quality of Control Center of Shanghai, No 180 Fenglin Road, Shanghai 200032, China. ${ }^{7}$ Department of Nephrology, Xiamen Branch, Zhongshan Hospital, Fudan University, No 668 Jinhu Road, Xiamen 361015, Fujian, China. ${ }^{8}$ Department of Cardiovascular Surgery, Zhongshan Hospital, Shanghai Medical College, Fudan University, No 180 Fenglin Road, Shanghai 200032, China.

Received: 24 January 2017 Accepted: 2 August 2018

Published online: 14 August 2018

\section{References}

1. Demir A, Yarali N, Fisgin T, Duru F, Kara A. Most reliable indices in differentiation between thalassemia trait and iron deficiency anemia. Pediatrics international : official journal of the Japan Pediatric Society. 2002; 44(6):612-6.

2. Sun XP, Chen WM, Sun ZJ, Ding XS, Gao XY, Liang SW, et al. Impact of red blood cell distribution width on long-term mortality in patients with STelevation myocardial infarction. Cardiology. 2014;128(4):343-8. 
3. Pascual-Figal DA, Bonaque JC, Manzano-Fernandez S, Fernandez A, Garrido IP, Pastor-Perez F, et al. Red blood cell distribution width predicts newonset anemia in heart failure patients. Int J Cardiol. 2012;160(3):196-200.

4. Liu T, Shao Q, Miao S, Liu E, Xu G, Yuan R, et al. Red cell distribution width as a novel, inexpensive marker for paroxysmal atrial fibrillation. Int J Cardiol. 2014;171(2):e52-3.

5. Zhao K, Li YJ, Gao S. Role of red blood cell distribution in predicting drugeluting stent restenosis in patients with stable angina pectoris after coronary stenting. Coron Artery Dis. 2015;26(3):220-4.

6. Wang $H$, Xu H, Wang X, Wu R, Gao X, Jin Q, et al. Red blood cell distribution width to platelet ratio is related to histologic severity of primary biliary cirrhosis. Medicine. 2016;95(11):e3114.

7. Karagoz E, Tanoglu A, Ulcay A, Erdem H, Turhan V, Kara M, et al. Mean platelet volume and red cell distribution width to platelet ratio for predicting the severity of hepatic fibrosis in patients with chronic hepatitis C. Eur J Gastroenterol Hepatol. 2016;28(7):744-8.

8. Zorlu A, Bektasoglu G, Guven FM, Dogan OT, Gucuk E, Ege MR, et al. Usefulness of admission red cell distribution width as a predictor of early mortality in patients with acute pulmonary embolism. Am J Cardiol. 2012; 109(1):128-34

9. Tertemiz KC, Ozgen Alpaydin A, Sevinc C, Ellidokuz H, Acara AC, Cimrin A. Could "red cell distribution width" predict COPD severity? Rev Port Pneumol. 2016;22(4):196-201

10. AHRQ. KDIGO clinical practice guideline for acute kidney injury. Kidney Int Suppl. 2012;2:1-138.

11. Zou Z, Zhuang Y, Liu L, Shen B, Xu J, Luo Z, et al. Role of body mass index in acute kidney injury patients after cardiac surgery. Cardiorenal Med. 2017; 8(1):9-17.

12. Docci D, Delvecchio C, Gollini C, Turci F, Baldrati L, Gilli P. Red blood cell volume distribution width (RDW) in uraemic patients on chronic haemodialysis. The International journal of artificial organs. 1989;12(3):170-4.

13. Peng F, Li Z, Zhong Z, Luo Q, Guo Q, Huang F, et al. An increasing of red blood cell distribution width was associated with cardiovascular mortality in patients on peritoneal dialysis. Int J Cardiol. 2014;176(3):1379-81.

14. Yoon HE, Kim SJ, Hwang HS, Chung S, Yang CW, Shin SJ. Progressive rise in red blood cell distribution width predicts mortality and cardiovascular events in end-stage renal disease patients. PLoS One. 2015;10(5):e0126272

15. Sicaja M, Pehar M, Derek L, Starcevic B, Vuletic V, Romic Z, et al. Red blood cell distribution width as a prognostic marker of mortality in patients on chronic dialysis: a single center, prospective longitudinal study. Croatian medical journal. 2013;54(1):25-32

16. Kurtul A, Yarlioglues M, Murat SN, Demircelik MB, Acikgoz SK, Ergun G, et al. Red cell distribution width predicts contrast-induced nephropathy in patients undergoing percutaneous coronary intervention for acute coronary syndrome. Angiology. 2015;66(5):433-40.

17. Yao HM, Sun TW, Zhang XJ, Shen DL, Du YY, Wan YD, et al. Red blood cell distribution width and long-term outcome in patients undergoing percutaneous coronary intervention in the drug-eluting stenting era: a twoyear cohort study. PLoS One. 2014;9(4):e94887.

18. Dabbah S, Hammerman H, Markiewicz W, Aronson D. Relation between red cell distribution width and clinical outcomes after acute myocardial infarction. Am J Cardiol. 2010;105(3):312-7.

19. Mizuno A, Ohde S, Nishizaki Y, Komatsu Y, Niwa K. Additional value of the red blood cell distribution width to the Mehran risk score for predicting contrast-induced acute kidney injury in patients with ST-elevation acute myocardial infarction. J Cardiol. 2015;66(1):41-5.

20. Akin F, Celik O, Altun I, Ayca B, Ozturk D, Satilmis S, et al. Relation of red cell distribution width to contrast-induced acute kidney injury in patients undergoing a primary percutaneous coronary intervention. Coron Artery Dis. 2015;26(4):289-95.

21. Pearson TA, Mensah GA, Alexander RW, Anderson JL, Cannon RO 3rd, Criqui $M$, et al. Markers of inflammation and cardiovascular disease: application to clinical and public health practice: a statement for healthcare professionals from the Centers for Disease Control and Prevention and the American Heart Association. Circulation. 2003;107(3):499-511.

22. Zakkar M, Guida G, Suleiman MS, Angelini GD. Cardiopulmonary bypass and oxidative stress. Oxidative Med Cell Longev. 2015;2015:189863.

23. Laffey JG, Boylan JF, Cheng DC. The systemic inflammatory response to cardiac surgery: implications for the anesthesiologist. Anesthesiology. 2002; 97(1):215-52.
24. Christen S, Finckh B, Lykkesfeldt J, Gessler P, Frese-Schaper M, Nielsen P, et al. Oxidative stress precedes peak systemic inflammatory response in pediatric patients undergoing cardiopulmonary bypass operation. Free Radic Biol Med. 2005;38(10):1323-32.

25. Pierce CN, Larson DF. Inflammatory cytokine inhibition of erythropoiesis in patients implanted with a mechanical circulatory assist device. Perfusion. 2005;20(2):83-90.

26. Scharte M, Fink MP. Red blood cell physiology in critical illness. Crit Care Med. 2003;31(12 Suppl):S651-7.

27. Ghali JK. Anemia and heart failure. Curr Opin Cardiol. 2009;24(2):172-8,

28. Laftah AH, Sharma N, Brookes MJ, McKie AT, Simpson RJ, Iabal TH, et al. Tumour necrosis factor alpha causes hypoferraemia and reduced intestinal iron absorption in mice. The Biochemical journal. 2006;397(1):61-7.

29. Purtle SW, Moromizato T, McKane CK, Gibbons FK, Christopher KB. The association of red cell distribution width at hospital discharge and out-ofhospital mortality following critical illness*. Crit Care Med. 2014;42(4):918-29.

30. Patel KV, Ferrucci L, Ershler WB, Longo DL, Guralnik JM. Red blood cell distribution width and the risk of death in middle-aged and older adults. Arch Intern Med. 2009;169(5):515-23.

31. Perlstein TS, Weuve J, Pfeffer MA, Beckman JA. Red blood cell distribution width and mortality risk in a community-based prospective cohort. Arch Intern Med. 2009:169(6):588-94.

32. Weiss G, Goodnough LT. Anemia of chronic disease. N Engl J Med. 2005; 352(10):1011-23.

33. Hunziker S, Celi LA, Lee J, Howell MD. Red cell distribution width improves the simplified acute physiology score for risk prediction in unselected critically ill patients. Crit Care. 2012;16(3):R89.

34. Park TS, Zambidis ET. A role for the renin-angiotensin system in hematopoiesis. Haematologica. 2009;94(6):745-7.

35. Vlahakos DV, Marathias KP, Madias NE. The role of the renin-angiotensin system in the regulation of erythropoiesis. American journal of kidney diseases : the official journal of the National Kidney Foundation. 2010;56(3):558-65.

36. Pongstaporn W, Bunyaratavej A. Hematological parameters, ferritin and vitamin B12 in vegetarians. J Med Assoc Thail. 1999;82(3):304-11.

37. Morgan DL, Peck SD. The use of red cell distribution width in the detection of iron deficiency in chronic hemodialysis patients. Am J Clin Pathol. 1988; 89(4):513-5.

38. Kaskel FJ, Bamgbola OF. Validation of a composite scoring scheme in the diagnosis of folate deficiency in a pediatric and adolescent dialysis cohort. Journal of renal nutrition : the official journal of the Council on Renal Nutrition of the National Kidney Foundation. 2008;18(5):430-9.

39. Forhecz Z, Gombos T, Borgulya G, Pozsonyi Z, Prohaszka Z, Janoskuti L. Red cell distribution width in heart failure: prediction of clinical events and relationship with markers of ineffective erythropoiesis, inflammation, renal function, and nutritional state. Am Heart J. 2009;158(4):659-66.

Ready to submit your research? Choose BMC and benefit from:

- fast, convenient online submission

- thorough peer review by experienced researchers in your field

- rapid publication on acceptance

- support for research data, including large and complex data types

- gold Open Access which fosters wider collaboration and increased citations

- maximum visibility for your research: over $100 \mathrm{M}$ website views per year

At $\mathrm{BMC}$, research is always in progress.

Learn more biomedcentral.com/submissions 